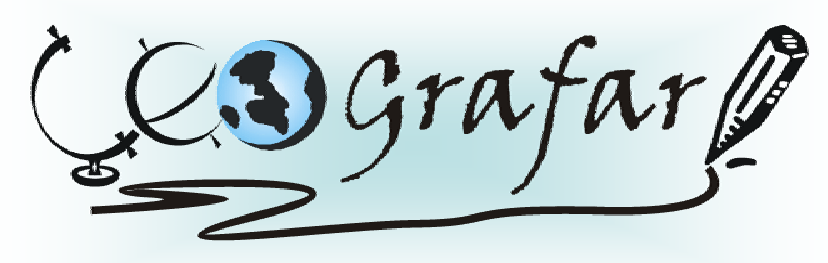

Revista Eletrônica do Programa de Pós-Graduação em Geografia - UFPR

\title{
AVALIAÇÃO DA EROSÃO ENTRE SULCOS EM SOLOS DE DIFERENTES CLASSES DE USO NA BACIA DO RIO DA BUCHA (PR), ATRAVÉS DO APARELHO DE INDERBITZEN
}

\author{
CLARICE FARIAN DE LEMOS ${ }^{1}$; CLAUDINEI TABORDA DA SILVEIRA ${ }^{2}$; JOSÉ \\ ROGÉRIO MILANI ${ }^{3}$; CHISATO OKA-FIORI ${ }^{4}$; ALBERTO PIO FIORI ${ }^{5}$
}

\begin{abstract}
RESUMO - O objetivo deste trabalho foi avaliar a erosão entre sulcos, através dos resultados da simulação de perda de solos e taxa de erosão no aparelho de Inderbitzen. O ensaio foi feito em quatro amostras de solo da bacia do rio da Bucha, em Campina Grande do Sul, Paraná. Esses resultados foram avaliados em função do tempo (1, 4, 6 e 10 minutos), considerando a composição granulométrica, matéria orgânica e os índices físicos do solo (densidade do solo seco, índice de vazios e porosidade total). As amostras representam três distintas classes de uso: áreas urbanizadas ou em fase de urbanização (P1), áreas de cultivo, pastagem, gramíneas e outras formas de vegetação rasteira no terço inferior da vertente (P2) e terço superior (P3) e áreas com predomínio de vegetação arbórea (P4). Nos resultados obtidos, a amostra P3 apresentou menor porosidade e menor índice de vazios, e maiores valores na perda de solos e na taxa de erosão, mesmo apresentando características granulométricas e de posição na vertente semelhantes à amostra P4. As amostras P1 e P2 estão localizadas na mesma toposseqüência (planície fluvial), sendo que P1 resultou numa maior perda de solo e taxa de erosão, e menor porosidade e índice de vazios, comparados a P2. Esses resultados confirmam a ação das atividades antrópicas na modificação das características físicas do solo, propiciando o aumento nos processos erosivos.
\end{abstract}

Palavras-chave: bacia hidrográfica, erodibilidade, perda de solos.

\section{ASSESSMENT OF INTERRILL EROSION IN SOILS OF DIFFERENT LAND USE CLASSES IN BUCHA RIVER'S BASIN'S (PR), THROUGH INDERBITZEN DEVICE}

\begin{abstract}
The objective this paper is to carry the comparative evaluation of the entre sulcos erosion, through the results of the simulation in loss soil and erosion ratio, in the device of Inderbitzen. The tests had been made in four soil samples, in Bucha River's Basin, in Campina Grande do Sul - Paraná. These results had been evaluated and understood in analytical way in function of the time (1, 4, 6 and 10 minutes), considering grain size composition, organic matter and the soil index properties (natural water content, void ratio and total porosity). The samples represent three distinct class of land use: urbanized areas or leadins to ones (P1), areas with cultivation, pasture, grass and other forms of low vegetation in the lower third of the slope (P2) and the upper third of the slope (P3) and areas with predominance of tree vegetation (P4). Results showed that the sample P3 presented minor porosity and void ratio, and greatens values in the loss soil and erosion ratio, same presented characteristic grained and of position in hill similar when P4 sample. The samples P1 and P2 are located in the same toposequel (fluvial plain), but P1 resulted in a bigger loss of soil and speed of erosion, and minor porosity and void ratio, compared whit $\mathrm{P} 2$. These results confirm the action of the anthropic activities in the modification of the physical characteristics of the soil, propitiating the increase in the erosive processes.
\end{abstract}

Key-words: drainage basin, erodibility, loss soil.

\footnotetext{
${ }^{1}$ Doutoranda de Geologia Ambiental da Universidade Federal do Paraná, claricefarian@hotmail.com;

2 Doutorando de Geografia da Universidade Federal do Paraná, claudineits@pop.com.br

${ }^{3}$ Doutorando de Geografia da Universidade Federal do Paraná, jirmilani@onda.com.br

${ }^{4}$ Professora Doutora do Programa de Pós-Graduação em Geografia da Universidade Federal do Paraná, chisato@ufpr.br

${ }^{5}$ Professor Doutor do Programa de Pós-Graduação em Geologia da Universidade Federal do Paraná, fiori@ufpr.br
} 


\section{INTRODUÇÃO}

Na configuração do cenário brasileiro, um dos principais fenômenos geoambientais que traz grande prejuízo à sociedade é a erosão do solo, entendida aqui, segundo a concepção de Bertoni e Lombardi Neto (1999), como o processo de desprendimento e arraste das partículas do solo pela ação da água.

Nos ambientes onde a água, por meio da precipitação, é o agente que deflagra a erosão, o processo inicia com a chuva precipitando sobre uma determinada superfície e, se o volume da água for maior que a capacidade de infiltração, terá inicio o escoamento superficial, provocando, assim, a erosão entre sulcos.

Portanto, a erosão do solo tem causas relacionadas à própria natureza da região, tais como: quantidade e distribuição das chuvas; declividade, comprimento e forma das encostas; tipo de cobertura vegetal e propriedades químicas e físicas dos solos.

As propriedades do solo que influenciam nos processos erosivos, de acordo com Silva et al. (2003), são: a) textura, compreendida como a distribuição do tamanho de partículas que compõe o solo, cujas características dependem do material originário e dos agentes naturais da sua formação; b) estrutura, sendo a forma como se arranjam as partículas do solo, influenciando na permeabilidade à água e resistência à erosão, essa característica pode ser modificada pelo tipo de uso do solo e emprego de práticas de manejo, incorporação de matéria orgânica, compactação e outros; c) porosidade, que representa a porção de espaços ocupados por fluídos em relação ao espaço ocupado pela massa de solo; d) matéria orgânica, que apresenta grande importância no controle da erosão, modificando a estrutura e melhorando as condições de aeração e de retenção de água nos solos argilosos, e nos solos arenosos permite a aglutinação de partículas, melhorando a estrutura, diminuindo os poros e aumentando a capacidade de retenção da água.

Apesar da erosão do solo ser um fenômeno natural, a sua intensificação e aceleração ocorrem devido ao desequilíbrio provocado pela ocupação do homem sobre o espaço, que ocasiona, em muitos casos, mudanças na dinâmica natural da paisagem.

Há, atualmente, distintos métodos que visam compreender, mensurar, quantificar, comparar e/ou avaliar os processos de erosão. Os métodos podem ser agrupados em modelos determinísticos, probabilísticos ou qualitativos e ensaios de parâmetros físicos do solo em laboratório. 
Uma proposta de avaliar a susceptibilidade erosiva do solo, por meio de ensaio laboratorial, foi apresentada por Inderbitzen (1961). Esse ensaio baseia-se no aparelho de Inderbitzen, que consiste em uma rampa metálica, com inclinação variável, onde é fixado um anel metálico contendo a amostra de solo. A simulação do escoamento superficial é feita sobre essa rampa, permitindo observar e comparar o processo erosivo em uma amostra de solo.

No entanto, devido à falta de precisão, os resultados do teste devem ser considerados como qualitativos, pois indicam o comportamento da erodibilidade apenas na ação do escoamento de água em sua superfície (INDERBITZEN, 1961).

Esse aparelho foi utilizado pela primeira vez no Brasil, como ensaio de avaliação da erodibilidade, pelo Instituto de Pesquisas Rodoviárias - IPR, no período de 1975 a 1978, em pesquisas sobre estabilidade de taludes que visavam apresentar recomendações para proteção contra erosão (BRASIL, 1979).

Desde então, outros trabalhos vêm sendo desenvolvidos no país utilizando-se da idéia original do aparelho de Inderbitzen. Dentre esses trabalhos destacam-se os de Fonseca e Ferreira (1981), que o consideraram um instrumento útil na determinação da erodibilidade dos solos e os de Fácio (1991) e Fácio e Carvalho (1994), que fizeram algumas adaptações dimensionais no aparelho original de Inderbitzen e propuseram a normatização desse ensaio. Além desses, tem-se Santos (1997) e Santos e Carvalho (1997), identificaram horizontes mais susceptíveis à erosão por fluxo superficial; Bastos (1999) e Bastos et al. (2001), propõem que os resultados sejam expressos em peso seco do solo erodido pela área da amostra $\left(\mathrm{g} \mathrm{cm}^{-2}\right)$ e plotados em relação ao tempo de ensaio (min); Fragassi e Marques (2001), propõem um aparelho de Inderbitzen mais versátil, visando facilitar a execução dos ensaios e ampliar o estudo dos processos erosivos; Freire (2001), sugere um ensaio que represente as condições do solo no campo durante as precipitações atmosféricas, denominado de Grau de Erodibilidade do Solo; Lemos (2002), pretendendo identificar a erodibilidade relacionada à erosão entre sulcos pelo escoamento superficial da água e ação da chuva, em áreas com plantio direto e plantio convencional, utiliza um simulador de chuva acoplado ao equipamento de Inderbitzen; Chamecki (2002) e Chamecki e Silva (2003a, 2003b) avaliaram a susceptibilidade de erosão em solo arenoso e argiloso e também em diferentes estados umidade. 
Referenciando-se nessas experiências, o objetivo deste trabalho é fazer a avaliação comparativa da erosão entre sulcos, através do aparelho de Inderbitzen e das análises dos índices físicos do solo, em amostras que visam contemplar três diferentes classes de cobertura do solo: áreas urbanizadas ou em fase de urbanização; áreas de cultivo, pastagem, gramíneas e outras formas de vegetação rasteira e áreas com predomínio de vegetação arbórea, pertencentes à bacia do rio da Bucha, no município de Campina Grande do Sul - Paraná.

A opção em comparar a simulação nessas classes remete-se a idéia de que, além das características físicas e naturais de cada solo, seu uso e cobertura influenciam diretamente na erosão entre sulcos, pois a ação antrópica modifica algumas das suas propriedades primárias.

\section{Localização E Caracterização Da Bacia Do Rio Da Bucha}

A bacia do rio da Bucha é uma sub-bacia do rio Timbú, ambas integram a bacia hidrográfica do Irai, que possuí um dos mais importantes reservatórios de abastecimento de água para a Região Metropolitana de Curitiba. Possuí área de 7,68 km², situando-se no município de Campina Grande do Sul - PR, entre as coordenadas geográficas: latitudes $25^{\circ}$ $19^{\prime} 28^{\prime \prime}$ e $25^{\circ} 21^{\prime} 37^{\prime \prime}$ sul e as longitudes $49^{\circ} 05^{\prime} 38^{\prime \prime}$ e $49^{\circ} 08^{\prime} 07^{\prime \prime}$ oeste (Figura 01).

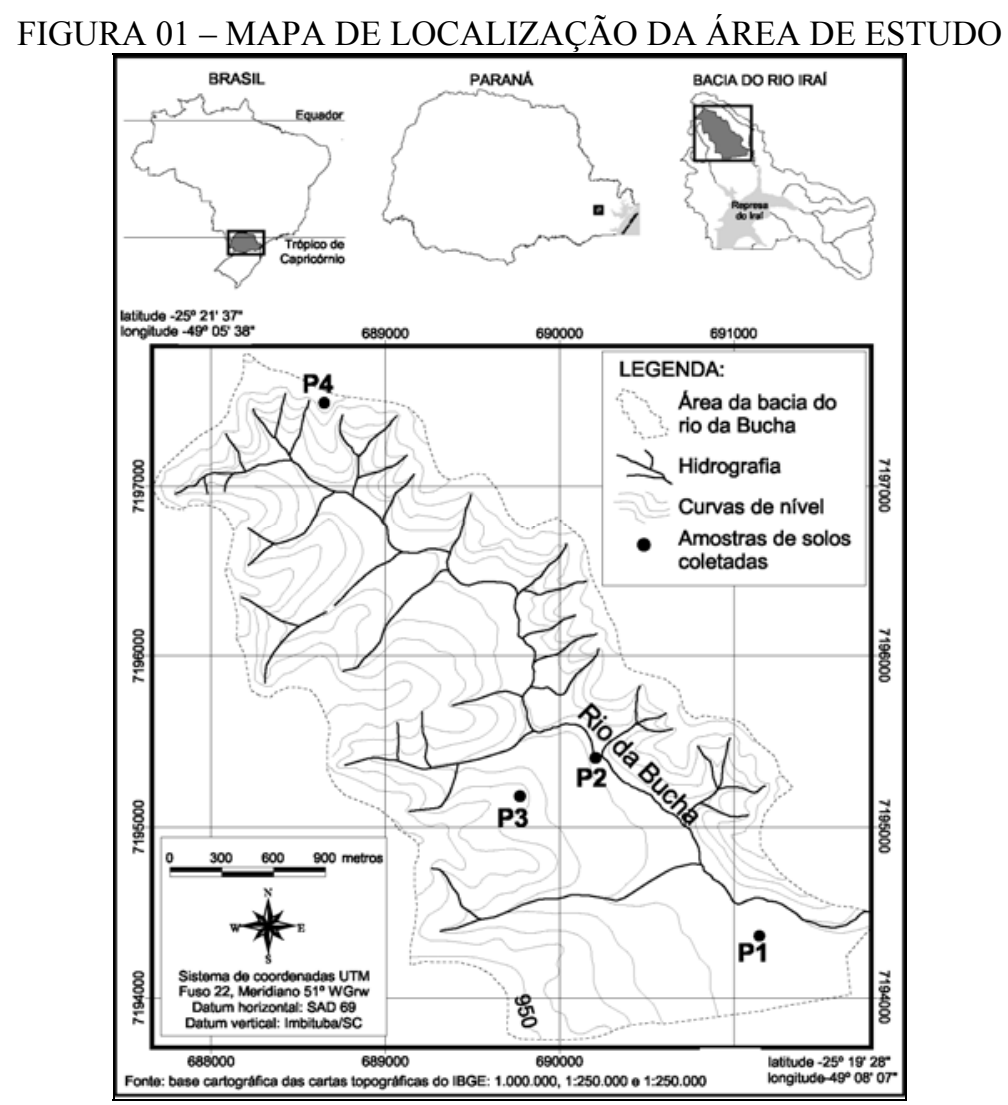


De acordo com Santos et al. (2006), a bacia do rio da Bucha está situada na unidade morfoescultural do Primeiro Planalto Paranaense, na sub-unidade morfoescultural denominada de Planalto de Curitiba, cujas características de relevo predominantes são: dissecação média, topos alongados e aplainados, vertentes convexas e vales em forma de "V", sobre o embasamento litológico da Formação Guabirotuba. É composta também por sedimentos recentes, situados na planície aluvial do canal principal. Seu gradiente altitudinal é de 80 metros, variando entre as cotas 900 a 980 metros acima do nível do mar.

Os solos presentes na bacia, de acordo com as unidades mapeadas por Lima (2005) (Figura 02) são: a) CXvd - Cambissolo Háplico Ta Distrófico típico substrato argilitos; b) $\mathrm{CHa}+\mathrm{CHd}$ - associação Cambissolo Húmico Alumínico típico + Cambissolo Húmico Distrófico típico ambos substrato argilitos; c) CHa+RLd - associação Cambissolo Húmico Alumínico típico + Neossolo Litólico Distrófico típico ambos substrato argilitos e arcósios; d) GXve - Gleissolo Háplico Ta Eutrófico típico; e) OYs - Organossolo Mésico Sáprico típico; f) Lvd - Latossolo Vermelho Distrófico típico; g) Área urbana - ocorrência de antropogênese nos solos.

\section{FIGURA 02 - MAPA DE SOLOS DA BACIA DO RIO DA BUCHA}

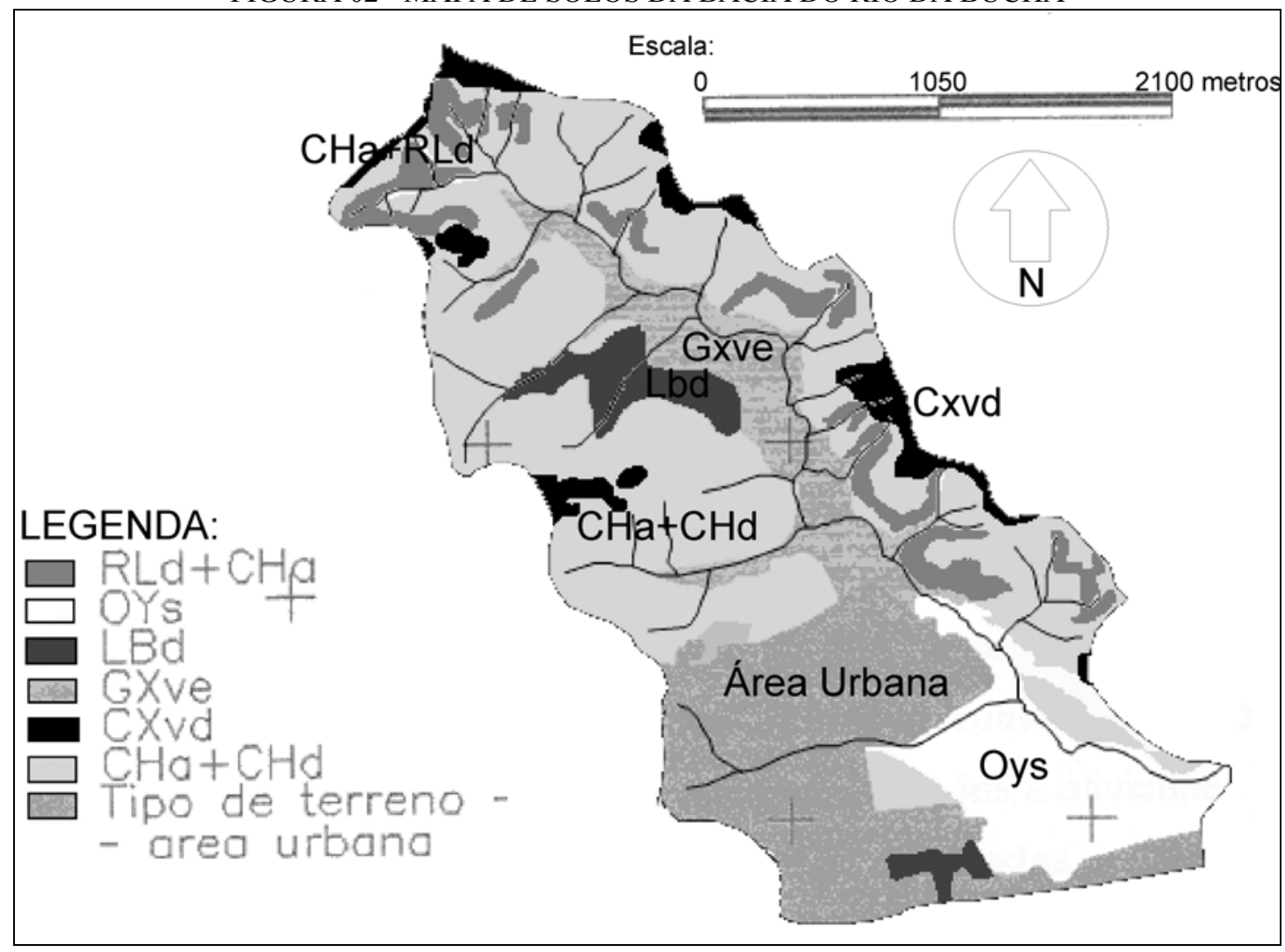

Fonte: Modificado de Lima (2005) 
Segundo a classificação de climática de Köppen, distingue-se na área de estudo, dentre os tipos climáticos do estado do Paraná, a classe $\mathrm{Cfb}$, definido como subtropical úmido mesotérmico. Apresenta no mês mais frio, temperatura média inferior a $18^{\circ} \mathrm{C}$ e verão fresco com temperatura média inferior a $22{ }^{\circ} \mathrm{C}$, não apresentando estação seca definida e sujeita a geadas severas (IAPAR, 2007).

No que diz respeito ao uso e ocupação do solo, baseando-se em análise de campo com auxílio de imagem de satélite Ikonos, distingui-se três principais classes de uso: áreas com predomínio de vegetação arbórea, áreas urbanizadas ou em fase de urbanização e áreas de cultivo, pastagem, gramíneas e outras formas de vegetação rasteira (Figura 03).

FIGURA 03 - MAPA DE USO E OCUPAÇÃO DO SOLO NA BACIA DO RIO DA BUCHA

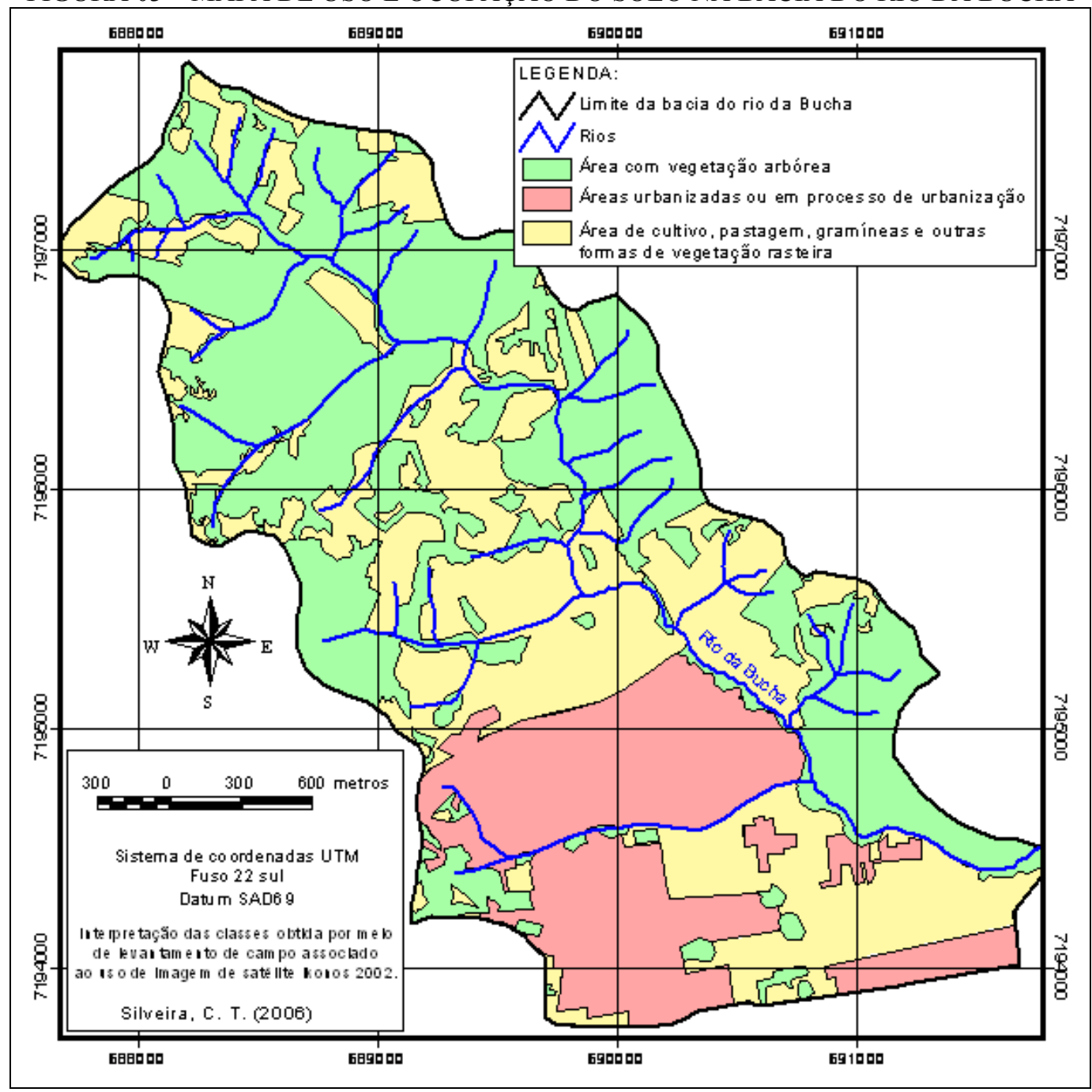

Avaliando a distribuição espacial no mapa de uso e ocupação do solo, nota-se o predomínio de áreas de vegetação arbórea, entendidas como floresta secundária em estágios inicial, intermediário ou avançado de sucessão associado algumas vezes à silvicultura, 
localizados principalmente no alto curso da bacia. As áreas urbanizadas ou em processo de urbanização, de maior densidade demográfica, situam-se no baixo curso do rio da Bucha, especificamente em sua margem direita. A classe que contém como uso agrícola, pecuária, com gramíneas e outras formas de vegetação rasteira, localiza-se em maior parte no médio e baixo curso da bacia, e também em áreas dispersas no alto curso.

\section{METODOLOGIA}

Foram coletadas amostras de solos, retiradas de quatro locais diferentes da bacia do rio da Bucha (Figura 01). Os pontos escolhidos seguiram a idéia de avaliar a relação entre perda de solo e a taxa de erosão medida pelo aparelho de Inderbitzen e o uso do solo: área em processo de urbanização (P1), área de gramíneas no terço inferior de uma vertente (P2) e no terço superior (P3) e área de vegetação arbórea (P4).

Para a análise da erosão entre sulcos foi utilizado o aparelho de Inderbitzen (Figura 04). Esse equipamento é constituído de uma estrutura metálica que suporta uma rampa de $34 \mathrm{~cm}$ de largura e $78 \mathrm{~cm}$ de comprimento, com furo de $10 \mathrm{~cm}$ de diâmetro a $40 \mathrm{~cm}$ do início do escoamento, para o encaixe dos anéis com as amostras indeformadas. A estrutura possui um sistema que permite variar a inclinação da rampa de $10^{\circ}(17,63 \%)$ a $45^{\circ}(100 \%)$.

\section{FIGURA 04 - APARELHO DE INDERBITZEN}

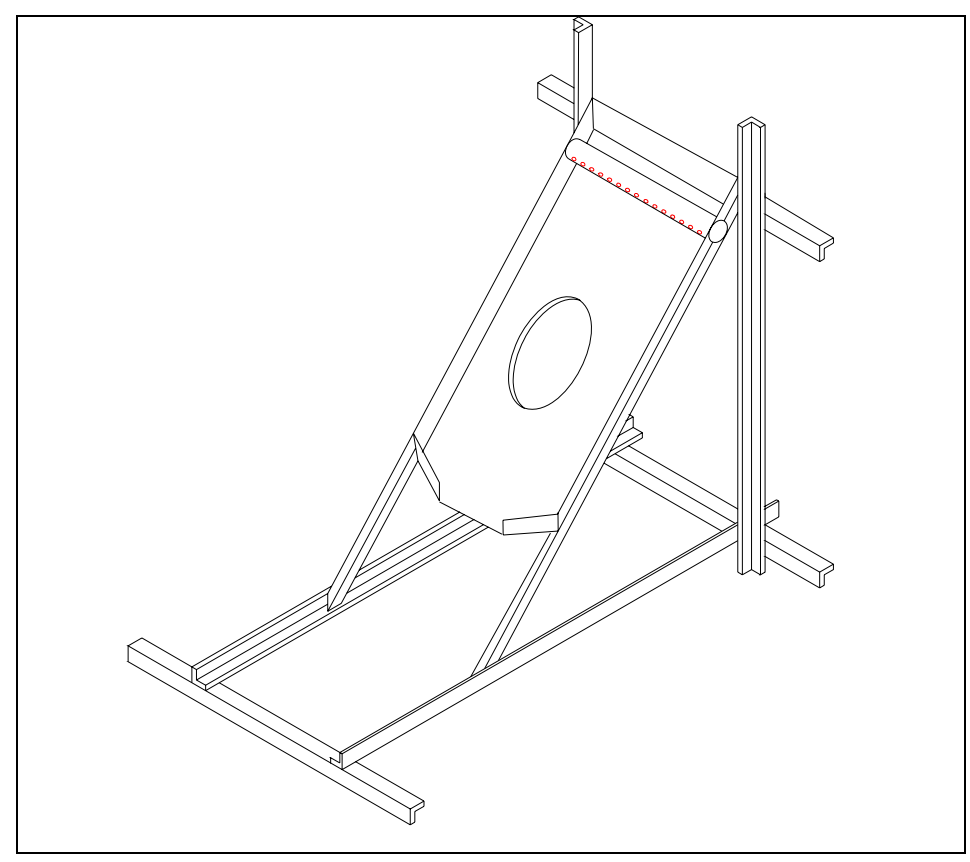

Fonte: Adaptado de Fonseca e Ferreira (1981) 
Para a simulação do escoamento superficial, sobre a rampa, utilizou-se um sistema de abastecimento elevado, através de um reservatório de cimento-amianto de $250 \mathrm{~L}$ de capacidade, colocado a 1,30 m do aparelho, e um controle da vazão foi por meio de registros.

Na coleta das amostras, após a escolha dos pontos e realizada a limpeza desses locais, retiraram-se às amostras indeformadas por meio de três anéis com $10 \mathrm{~cm}$ de diâmetro e $5 \mathrm{~cm}$ de profundidade para cada ponto de amostragem (Figura 05). Estas foram embaladas em sacos plásticos e devidamente etiquetadas, minimizando assim, a perda da umidade natural até serem utilizadas no ensaio de Inderbitzen.
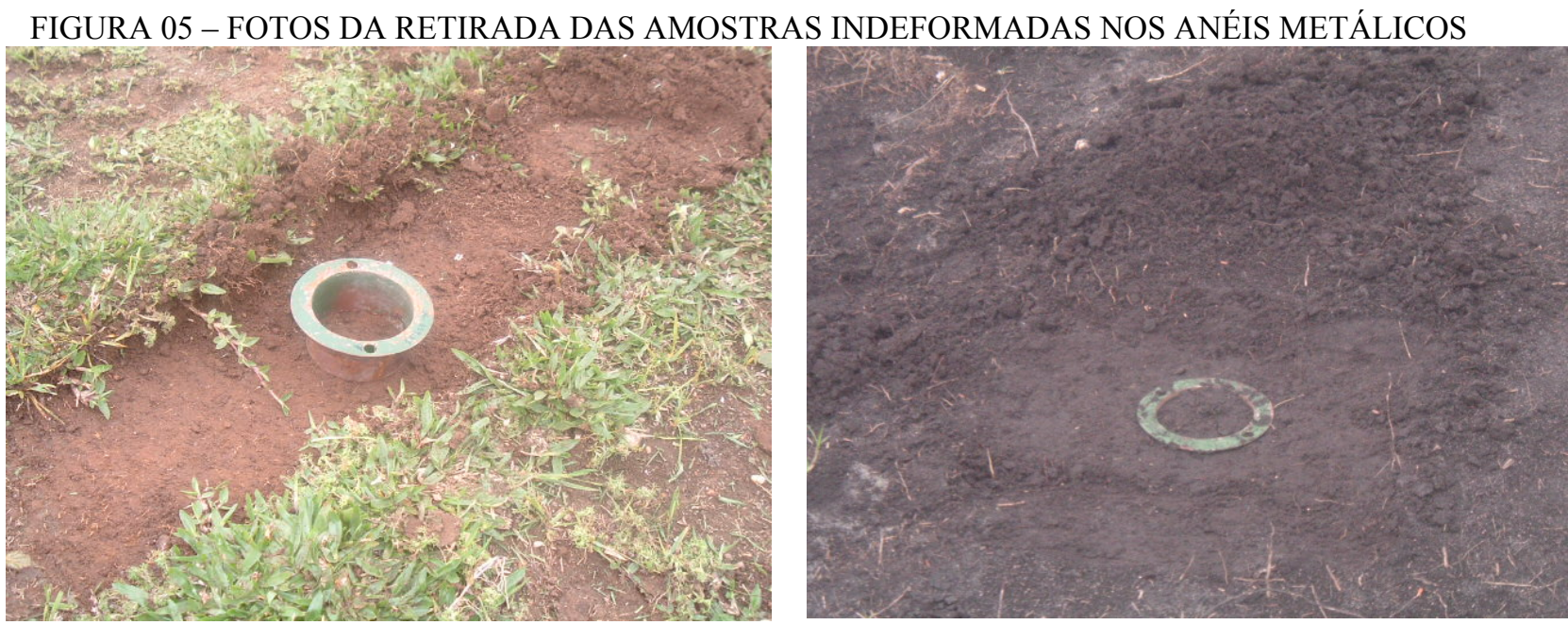

Após a retirada dos anéis, foram coletadas amostras deformadas para as análises físicas com, aproximadamente, $3 \mathrm{~kg}$ de cada material a uma profundidade de 0-10 $\mathrm{cm}$ da superfície do solo, para as análises físicas.

As amostras deformadas foram colocadas em recipientes identificados, espalhadas e destorroadas com as mãos, e seguiram para a execução dos seguintes ensaios físicos e determinações:

a) Análise granulométrica - fornecida pelo Laboratório de Análise de Minerais e Rochas LAMIR / UFPR. A classificação da textura dos solos adotada para representar o tamanho das partículas das amostras (diâmetros das partículas em $\mathrm{mm}$ ), seguiu a proposta do Massachusets Institute of Technology (M.I.T.) que é a mais difundida e utilizada no Brasil, conforme Garcez e Alvarez (1988);

b) Densidade de Partículas do Solo $\left(\gamma_{\mathrm{p}} ; \mathrm{g} \mathrm{cm}^{-3}\right)$ - Método do Balão Volumétrico, conforme metodologia da EMBRAPA (1997); 
c) Densidade do Solo Seco $\left(\gamma_{\mathrm{s}} ; \mathrm{g} \mathrm{cm}^{-3}\right)$ - Método da Proveta, conforme determinação da EMBRAPA (1997);

d) Índice de vazios $(\varepsilon)$ - calculado pela equação: $\varepsilon=\frac{\gamma_{g}}{\gamma_{s}}-1$, de acordo com Fiori e Carmignani (2001);

e) Porosidade Total $(\eta, \%)$ - calculada a partir da equação: $\eta=\left(1-\frac{\gamma_{s}}{\gamma_{g}}\right) \times 100$, conforme Fiori e Carmignani (op cit.);

f) Matéria Orgânica $\left(\mathrm{M}_{\mathrm{O}}, \%\right)$ - determinada através de amostras com pesos conhecidos, secas em estufas, queimadas dentro de cadinhos e colocadas na mufla, conforme o procedimento do Laboratório de Química, no Centro Politécnico / UFPR.

As amostras indeformadas, coletadas em anéis metálicos, foram utilizadas para o ensaio de erosão, realizado no Laboratório de Mecânica dos Solos - LAME / UFPR, através do aparelho de Inderbitzen (Figuras 06 e 07). Esse equipamento é o mesmo usado por Lemos (2002), porém foram adotados os seguintes parâmetros: declividade de rampa de $16^{\circ}$, o tempo de ensaio de 10 min e a vazão entre 10,91 e $12,93 \mathrm{ml} \mathrm{s}^{-1}$.

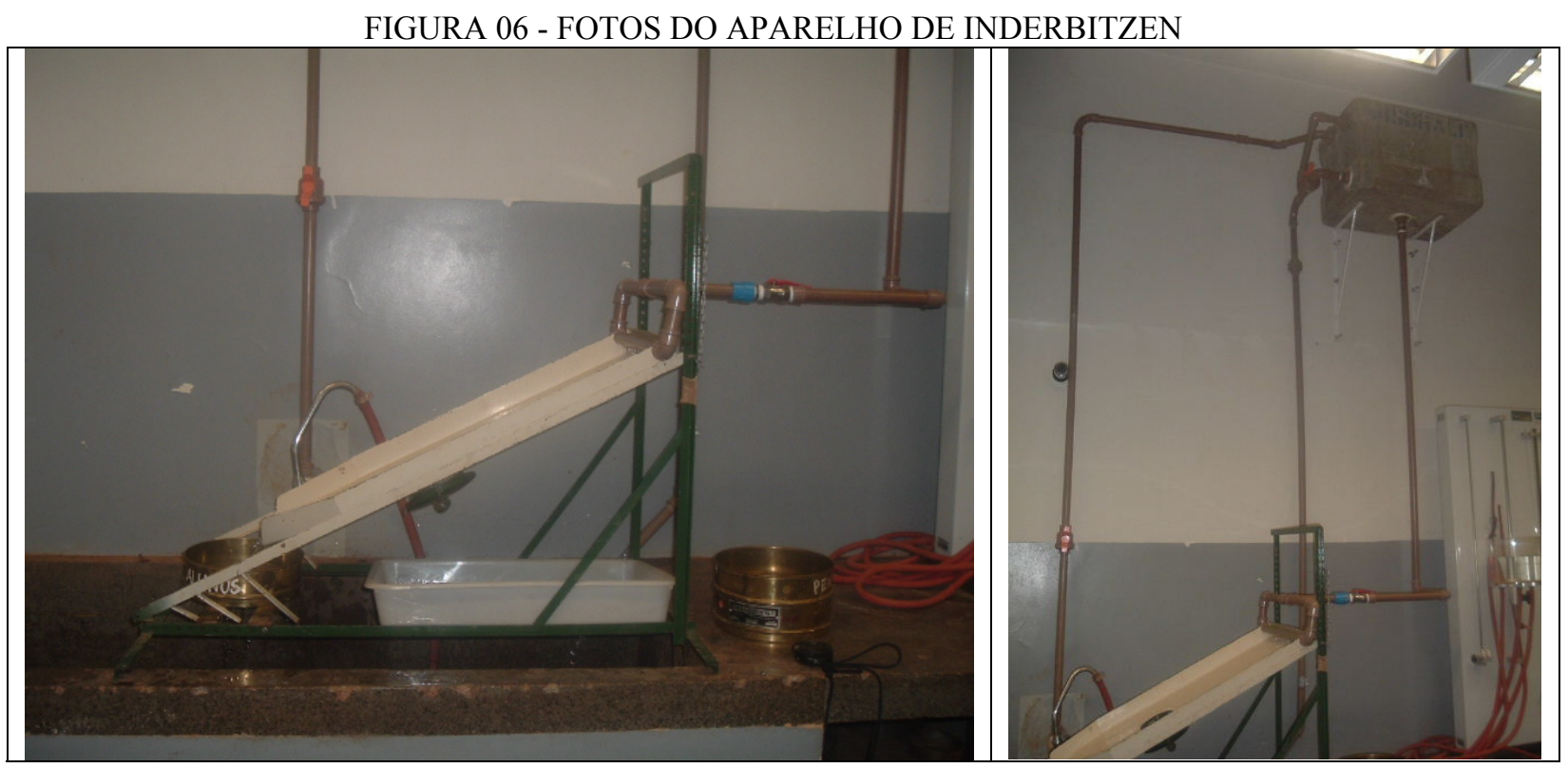




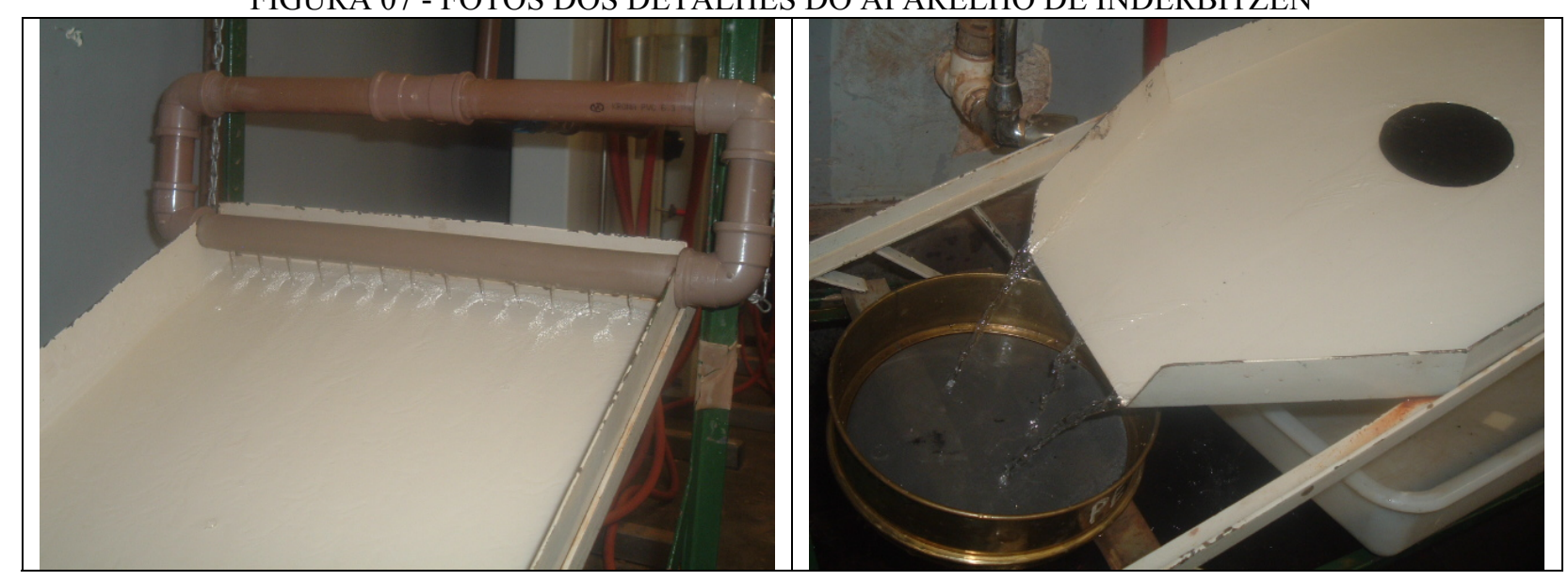

Os procedimentos para esse ensaio foram baseados em Lemos (2002). Depois de retirado o anel do plástico e ajustado a superfície da rampa coberta com papel filme, é realizada a regularização da vazão, deixando-se escoar a água por 5 min. A vazão foi medida no final de cada ensaio, coletando-se o volume de água no tempo de 45 segundos.

O ensaio é iniciado com a retirada do papel filme e o acionamento do cronômetro, simultaneamente. Nos tempos de 1, 4, 7, $10 \mathrm{~min}$, o material erodido foi coletado através da peneira com malha de $0,053 \mathrm{~mm}\left(\mathrm{n}^{\mathrm{o}} 270\right)$. O solo erodido foi colocado em cadinhos metálicos, com pesos conhecidos e devidamente identificado e, em seguida, levados à estufa por 24 h e após a secagem, pesados. Realizou-se três repetições do ensaio totalizando doze anéis.

Com as massas do material erodido foi possível apresentar os resultados sob forma de gráficos de perda de solo - ps $\left(\mathrm{g} \mathrm{cm}^{-2}\right)$ e taxa de erosão - ve $\left(\mathrm{g} \mathrm{cm}^{-2} \mathrm{hora}^{-1}\right)$ pelo tempo de ensaio (min), para facilitar as análises comparativas dos valores encontrados. Os resultados de todas as amostras indeformadas foram plotados, sendo que foi realizada a média das três análises para cada ponto de coleta e foi trabalhado com o resultado da amostra que mais se aproxima dessa média.

\section{RESULTADOS E DISCUSSÃO}

Quanto maior o tamanho de grão constituinte do solo maior é a infiltração de água no solo (GARCEZ e ALVAREZ, 2002), conseqüentemente, menor erosão entre sulcos. Porém, a influência antrópica pode mudar as características estruturais do solo e, assim, alterar essa 
lógica de que a textura está diretamente associada à infiltração. Isso é demonstrado pelo fato de que solos compactados são mais susceptíveis à erosão, segundo Derpsch et al (1991).

A matéria orgânica, também, representa grande importância no controle da erosão, devido à capacidade de retenção das águas de chuvas, segundo Silva et al. (2003), armazenando duas vezes seu peso em água. Além do mais, favorece atividades bióticas no solo, propiciando a existência de insetos e animais escavadores, conseqüentemente aumenta a porosidade e reduz a compactação.

A composição granulométrica e a quantidade de matéria orgânica estão apresentadas na Tabela 01. Nela observa-se maior concentração de matéria orgânica nas amostras P1 e P2, que estão localizadas próximas a áreas de planície fluvial. A amostra P1 apresenta maior valor de areia, a P2 de silte e P3 de argila.

TABELA 01 - COMPOSIÇÃO GRANULOMÉTRICA E MATÉRIA ORGÂNICA

\begin{tabular}{ccccc}
\hline Amostras & $\begin{array}{c}\text { Areia } \\
\left(\mathrm{g} \mathrm{kg}^{-1}\right)\end{array}$ & $\begin{array}{c}\text { Silte } \\
\left(\mathrm{g} \mathrm{kg}^{-1}\right)\end{array}$ & $\begin{array}{c}\text { Argila } \\
\left(\mathrm{g} \mathrm{kg}^{-1}\right) \\
<0,002 \mathrm{~mm}\end{array}$ & $\begin{array}{c}\mathrm{M}_{\mathrm{O}} \\
\left(\mathrm{g} \mathrm{kg}^{-1}\right)\end{array}$ \\
\hline P1 & 524,0 & 397,2 & 78,8 & 279,8 \\
P2 & 310,8 & 578,8 & 110,4 & 261,2 \\
P3 & 438,6 & 442,9 & 118,5 & 258,3 \\
P4 & 425,5 & 457,9 & 116,6 & 244,0 \\
\hline
\end{tabular}

ONDE: $\mathrm{M}_{\mathrm{O}}$ - MATÉRIA ORGÂNICA

O índice de vazios $(\varepsilon)$ e a porosidade total $(\eta)$, apresentados na Tabela 02, são importantes na caracterização da permeabilidade e compactação e se relacionam diretamente com o tipo de cobertura do solo. Para Beltrame e Taylor (1980) a compactação do solo limita a infiltração e a redistribuição da água no solo. Verifica-se no trabalho que tais índices estão relacionados com a erosão.

A amostra P4, do solo protegido pela cobertura vegetal de porte arbóreo, apresentou os maiores valores no índice de vazios e porosidade total; as amostras P1 e P3, cujas classes de uso foram definidas, respectivamente, como: área em processo de urbanização e área de gramíneas, com fluxo de veículos pesados (tratores), apresentaram os menores valores dos índices acima; na amostra P2, embora seja área de gramínea, não ocorre trânsito de veículos 
pesados sobre sua superfície. Esses resultados confirmam a hipótese de que o uso interfere diretamente nessas propriedades físicas do solo.

TABELA 02 - ÍNDICES FÍSICOS

\begin{tabular}{ccccc}
\hline Amostras & $\begin{array}{c}\gamma_{\mathrm{g}} \\
\left(\mathrm{g} \mathrm{cm}^{-3}\right)\end{array}$ & $\begin{array}{c}\gamma_{\mathrm{s}} \\
\left(\mathrm{g} \mathrm{cm}^{-3}\right)\end{array}$ & $\varepsilon$ & $\begin{array}{c}\eta \\
(\%)\end{array}$ \\
\hline \hline P1 & 2,49 & 1,08 & 1,31 & 56,68 \\
P2 & 2,44 & 1,02 & 1,40 & 58,38 \\
P3 & 2,42 & 1,05 & 1,30 & 56,52 \\
P4 & 2,46 & 0,99 & 1,50 & 59,93 \\
\hline
\end{tabular}

Onde: $\gamma_{\mathrm{p}}$ - Densidade de partículas do Solo; $\gamma_{\mathrm{s}}$ - Densidade do Solo Seco; $\varepsilon$ - Índice de Vazios e $\eta$ Porosidade Total.

Os resultados dos ensaios de Inderbitzen estão apresentados na forma de gráficos de perda de solo e taxa de erosão pelo tempo de realização do ensaio (Figuras 08 e 09). As curvas obtidas apresentaram resultados semelhantes às encontradas por Fonseca e Ferreira (1981), Fácio (1991), Santos (1997) e Lemos (2002).

FIGURA 08 - SIMULAÇÃO DE PERDA DE SOLO NO APARELHO INDERBITZEN

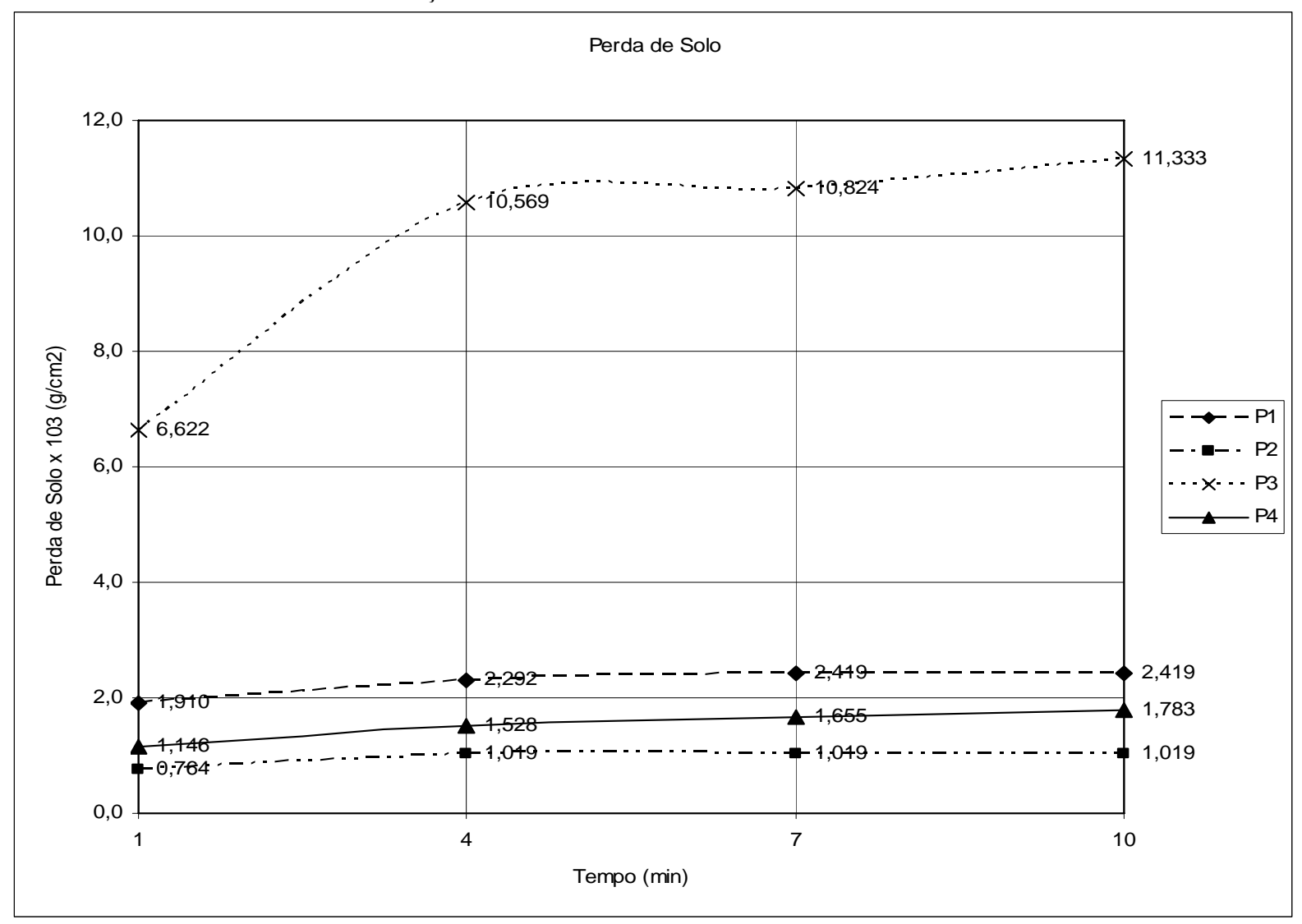


FIGURA 09 - SIMULAÇÃO TAXA DE EROSÃO NO APARELHO DE INDERBITZEN

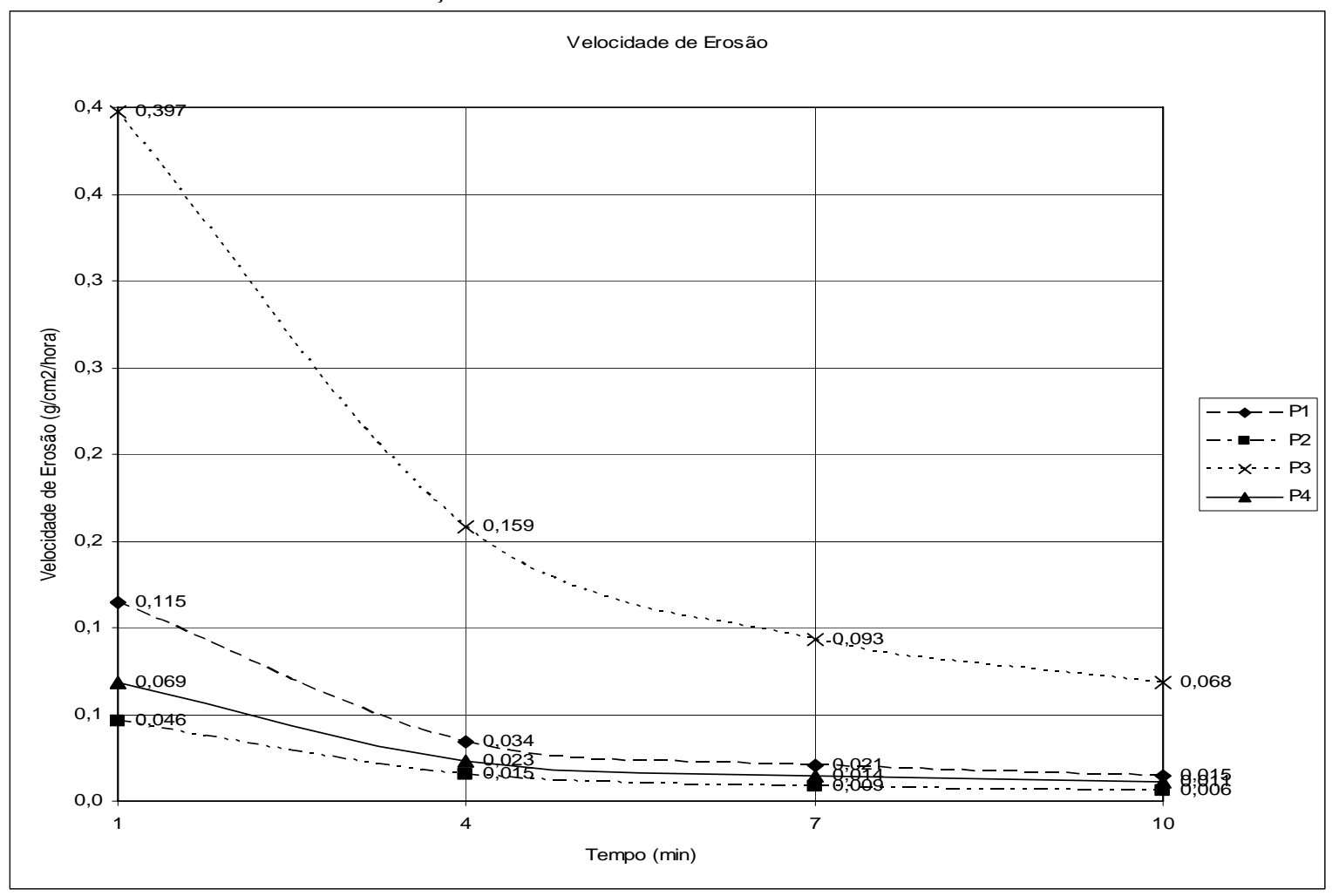

Avaliando as simulações analisadas nos ensaios de Inderbitzen, verificou-se que a amostra P3 apresentou os maiores valores de perda de solo e taxa de erosão. Tais resultados são compreendidos pelas características de uso, que refletem nas propriedades do solo: baixo índice de vazios, baixa porosidade e baixa densidade do solo seco, que demonstram a compactação do solo e, conseqüentemente, a redução da capacidade de infiltração e retenção da água nos espaços vazios, levando ao aumento da erosão entre sulcos.

$\mathrm{Na}$ amostra $\mathrm{P} 2$, os valores obtidos na simulação foram os mais baixos. Isso se deve ao fato de apresentar acumulo de matéria orgânica, associado a sua localização na bacia e, também, da interferência da forma de uso e ocupação que não propicia a compactação do solo, demonstrado pelas características físicas obtidas dessa amostra.

Embora P1 apresente a maior concentração de matéria orgânica entre todas as amostras, e portanto, hipoteticamente, deveria ter os menores valores de erosão devido a retenção da água, o resultado da simulação mostrou o contrário. A explicação encontrada está associada à maior compactação do solo exercida pelo tipo de uso, uma vez que está localizada numa área em processo de urbanização. Essa compactação é averiguada nos valores das propriedades físicas do solo: baixa porosidade e baixo índice de vazios. 
A amostra P4 apresentou características textural e topossequêncial e quantia de matéria orgânica semelhante à amostra P3, no entanto, sua classe de uso e ocupação, vegetação arbórea, exerce maior proteção do solo, logo apresentou valores mais elevados de porosidade e índice de vazios e baixa densidade solo seco, demonstrando que representa solos pouco compactados, que favorecem a infiltração, minimizando a erosão entre sulcos. Este fato foi confirmado nos valores de perda de solo e taxa de erosão obtidos nas simulações. Portanto, o que pôde ser verificado é que a amostra P3, embora apresente conformidade nas características granulométricas similares a amostra P4 e ambas as amostras tenham posição semelhante na vertente, revelou valores muito mais elevados na perda de solos e taxa de erosão, na simulação com o aparelho Inderbitzen. Tal diferença de resultados foi explicada quando avaliados os índices físicos, que são influenciados pelos tipos de uso, sendo que P3 apresentou menor porosidade e menor índice de vazios, pois sofre influência de tráfego de máquinas automotoras, e o segundo por possuir cobertura vegetal arbórea apresentou valores elevados de porosidade e índice de vazio e baixo densidade do solo seco.

O mesmo ocorreu nas amostras P1 e P2, uma vez que a localização toposseqüêncial de ambas é semelhante e apresentaram diferenças nos resultados simulados, P1 obteve valor mais alto de perda de solo e taxa de erosão, comparado com P2. Foi encontrada a mesma explicação ligada às práticas de uso, uma vez que a primeira se localiza em área em fase de urbanização e a segunda com vegetação de gramíneas sem tráfego de veículos, máquinas automotivas ou animais.

Esses resultados confirmam a ação das atividades antrópicas e suas práticas de uso na modificação das características físicas do solo, propiciando a alteração em algumas das propriedades físicas e, com isso, levando ao aumento dos processos erosivos.

\section{CONCLUSÕES}

A avaliação comparativa de erosão entre sulcos de quatro amostras de solo, em três diferentes classes de uso na bacia do rio da Bucha, através de simulação no aparelho de Inderbitzen e as análises das características físicas, conduziu as seguintes conclusões:

1) o processo de erosão entre sulcos apresentou ligação com as propriedades físicas do solo de porosidade e índice de vazios;

2) as curvas de perda de solo e de taxa de erosão pelo o tempo de duração do ensaio 
apresentaram-se bem definidas para o escoamento superficial, e permitiram comparar a erosão entre sulcos entre as amostras;

3) os resultados confirmam a ação das atividades antrópicas na modificação das características físicas do solo, propiciando o aumento nos processos erosivos.

\section{REFERÊNCIAS}

BASTOS, C. A. B.; MILITITSKY, J.; GEHLING, W. Y. Y. Proposta metodológica para avaliação geotécnica da erodibilidade de solos residuais não saturados. In: SIMPÓSIO NACIONAL DE CONTROLE DE EROSÃO, 7, 2001, Goiânia. Relação de Trabalhos. Goiânia: [s.n.], 2001.

BASTOS, C. A. B. Estudo geotécnico sobre a erodibilidade de solos residuais não saturados. Porto Alegre, 1999. 269 f. Tese (Doutorado em Engenharia Civil) - Escola de Engenharia, Universidade Federal do Rio Grande do Sul.

BELTRAME, L. F. S.; TAYLOR, J. C. Causas e efeitos da compatação do solo. Lavoura Arrozeira, Porto Alegre, v. 33, p. 59-62, 1980.

BERTONI, J.; LOMBARDI NETO, F. Conservação do Solo. 4. ed. São Paulo: Ícone, 1999. $355 \mathrm{p}$.

BRASIL. Ministério dos Transportes. Departamento Nacional de Estradas de Rodagem; Instituto de Pesquisas Rodoviárias. Divisão de Pesquisa. Pesquisa de estabilidade de taludes: recomendações para proteção de taludes contra erosão. Rio de Janeiro: IPR/DNER, 1979. $59 \mathrm{p}$.

CHAMECKI, P. R.; SILVA, E. T. Estudo geotécnico de erosão em laboratório, aplicado a uma argila da Formação Guabirotuba. In: SIMPÓSIO BRASILEIRO DE GEOSSINTÉTICOS, 4, CONGRESSO BRASILEIRO DE GEOTENICA AMBIENTAL, 5, 2003, Anais. Porto Alegre: Associação Brasileira de Mecânica dos Solos e Engenharia Geotécnica, 2003a.

CHAMECKI, P. R.; SILVA, E. T. Simulação de processos de erosão hídrica em solos através de metodologia laboratorial: aplicação a uma argila da formação Guabirotuba. In: CONGRESSO BRASILEIRO DE ENGENHARIA AGRÍCOLA, 32, 2003, Goiânia. Anais. Jaboticabal: Sociedade Brasileira de Engenharia Agrícola, 2003b.

CHAMECKI, P. R. Metodologias de laboratório para estudos de erosão hídrica em solos: aplicação a uma argila da Formação Guabirotuba. Curitiba, 2002. 274 f. Dissertação (Mestrado em Agronomia - área de concentração em Ciência do Solo) - Universidade Federal do Paraná.

DERPSCH, C. H. et al. Controle da erosão no Paraná, Brasil: sistemas de cobertura do solo, plantio direto e preparo conservacionista do solo. Eschborn, Alemanha: Gesellschaft fün Technische Zusammenarbeit (GTZ) - IAPAR, 1991. p. 47-51.

EMBRAPA - Empresa Brasileira de Pesquisa Agropecuária. Manual de métodos de análise de solo. 2. ed. rev. atual. Rio de Janeiro: Embrapa Solos, 1997.

FACIO, J. A.; CARVALHO, J. C. Estudo da Erodibilidade de Solos do Distrito Federal. In: CONGRESSO BRASILEIRO DE MECÂNICA DOS SOLOS E ENGENHARIA DE 
FUNDAÇÕES, 10, 1994, Foz do Iguaçu. Anais. Foz do Iguaçú: ABMS, 1994. v. 4. p. 12451252.

FÁCIO, J. A. Proposição de uma metodologia de estudo da erodibilidade dos solos do Distrito Federal. Brasília, 1991. 107 f. Dissertação (Mestrado em Geotecnia) - Departamento de Engenharia Civil, Faculdade de Tecnologia, Universidade de Brasília.

FIORI, A. P.; CARMIGNANI, L. Fundamentos de Mecânica dos Solos e das Rochas: aplicações na estabilidade de taludes. Curitiba: Editora da UFPR, 2001.

FONSECA, A. M. M. C. C.; FERREIRA, C. S. M. Metodologia para determinação de um índice de erodibilidade de solos. In: SIMPÓSIO BRASILEIRO DE SOLOS TROPICAIS EM ENGENHARIA, 1981, Rio de Janeiro. Anais. Rio de Janeiro: COPPE / UFRJ, CNPq, ABMS, 1981. p. 646-664.

FRAGASSI, P. F. M.; MARQUES, E. A. G. Desenvolvimento de uma nova versão do aparelho Inderbitzen. In: SIMPÓSIO NACIONAL DE CONTROLE DE EROSÃO, 7, 2001, Goiânia. Relação de trabalhos. Goiânia: [s.n.], 2001. 1 CD-ROM.

FREIRE, E. P. Ensaio de Inderbitzen modificado: um novo modelo para avaliação do grau de erodibilidade do solo. In: SIMPÓSIO NACIONAL DE CONTROLE DE EROSÃO, 7, 2001, Goiânia. Relação de trabalhos. Goiânia: [s.n.], 2001. 1 CD-ROM.

GARCEZ, L. N.; ALVAREZ, G. A. Hidrologia. 2. ed. São Paulo: Edgard Blüncher, 2002.

IAPAR. Classificação Climática do Estado do Paraná - Köppen; site: http://200.201.27.90/site/sma/Cartas_Climaticas/Cartas_Climaticas.htm, acesso em: $10 / 08 / 2007$.

INDERBITZEN, A. L. An erosion test for soils. Materials Research \& Standarts, v. 1, n. 7, Technical Note, p. 553-554, 1961.

LEMOS, C. F. Avaliação da erosão superficial em áreas de cultivo com plantio direto e plantio convencional, utilizando o aparelho de Inderbitzen. Curitiba, 2002. $82 \mathrm{f}$. Dissertação (Mestrado em Agronomia - área de concentração em Ciência do Solo) Universidade Federal do Paraná.

LIMA, M. R. Atributos de solos e macrófitas aquáticas flutuantes: uma contribuição à sustentabilidade agrícola e ambiental na bacia do rio Irai (PR). Curitiba, 2005. $111 \mathrm{f}$. Tese (Doutorado em Agronomia - Produção Vegetal) - Universidade Federal do Paraná.

SANTOS, R. M. M. Caracterização geotécnica e análise do processo evolutivo das erosões no município de Goiânia. Brasília, 1997. 120 f. Dissertação (Mestrado em Geotécnia) - Departamento de Engenharia Civil, Faculdade de Tecnologia, Universidade de Brasília.

SANTOS, R. M. M.; CARVALHO, J. C. Ensaios especiais para a previsão de fenômenos erosivos. In: SIMPÓSIO DE GEOLOGIA DO CENTRO-OESTE, 6, 1997. Anais. Cuiabá.: [s.n.], 1997. v. 1. p. 117-118.

SANTOS, L. J. C.; OKA-FIORI, C.; CANALI, N. E.; FIORI, A. P.; SILVEIRA, C. T.; SILVA, J. M. F.; ROSS, J. L. S. 2006. Mapeamento Geomorfológico do Estado do Paraná. Revista Brasileira de Geomorfologia, 07:03-11.

SILVA, A. M. da; SCHULZ, H. E.; CAMARGO, P. B. de. Erosão e hidrossedimentologia em bacias hidrográficas. São Carlos: RiMa, 2003. 